\title{
Thrombosis, an important piece in the COVID-19 puzzle: From pathophysiology to therapy
}

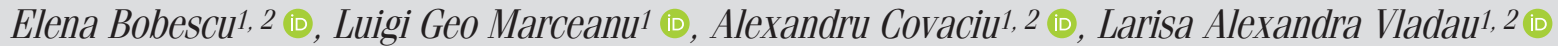 \\ ${ }^{1}$ Department of Medical and Surgical Specialties, Faculty of Medicine, Transilvania University of Brasov; Brasov- Romania \\ ${ }^{2}$ Department of Cardiology, Clinical County Emergency Hospital Brasov; Brasov-Romania
}

\begin{abstract}
A lot of data about coronavirus disease 2019 (COVID-19) have been already published; however, these still form only a part of the pandemic puzzle. Once we have all the pieces of the puzzle, we will be able to successfully treat this disease with its multiple challenges. COVID-19 has a high thrombogenic potential. In this study, we aimed to review published data about COVID-19 associated thrombosis from pathophysiology to treatment and the role in patient evolution. We searched for articles and studies published online through MEDLINE/PubMed database, Google Scholar, ScienceDirect, Wiley Online Library, and Nature Public Health Emergency Collection. We found numerous articles regarding COVID-19 infection but selected only those focused on thrombosis. D-dimers have a predictive value in identifying thrombosis and a high level correlates with the severity of the infection and death. Most patients who were on chronic anticoagulant therapy before contracting the virus had a better prognosis. Heparin has other favorable effects such as a direct antiviral and anti-inflammatory effect in addition to its anticoagulant effect. COVID-19 infections are frequently complicated by thrombotic pathology. High plasma level of D-dimers is a predictive factor for severe prognosis, and the recommended anticoagulant, associated with low mortality, is heparin followed by a direct oral anticoagulant. Randomized studies in large groups of patients and therapeutic guidelines are still needed on this subject.
\end{abstract}

Keywords: coronavirus disease 2019, thrombosis, anticoagulant agents, telemedicine

Cite this article as: Bobescu E, Marceanu LG, Covaciu A, Vladau LA. Thrombosis, an important piece in the COVID-19 puzzle: From pathophysiology to therapy. Anatol J Cardiol 2021; 25: 601-8.

\section{Introduction}

Coronavirus disease 2019 (COVID-19) infection has spread across the globe in an exponential manner causing the onset of a public health crisis and has quickly been declared a pandemic. More than ever, monitoring and diagnosing patients with this disease involves multidisciplinary teams. Tele-diagnosis and tele-monitoring are the only way to follow up quarantined patients for information about their status, progress, and recovery. Each patient will have a personalized diagnosis and treatment in correlation with the acute infectious disease and a history of associated diseases. Therefore, it is important to integrate a wide spectrum of published information and the results of the studies published thus far with the current medical practice as soon as possible.
In patients with COVID-19 infection, a high diversity of clinical signs and symptoms, ranging from no symptoms to interstitial pneumonia and progression to acute respiratory distress syndrome, accompanied by multiple system and organ failure can be observed $(1,2)$. Although pulmonary pathology is most common, cardiac injury is an important piece of the puzzle, frequently accompanied by thrombotic vascular complications. One of the biggest challenges facing the medical staff caring for patients with COVID-19 is the prevention and early diagnosis of vascular thromboembolism.

As this infection is recent, clinicians are currently facing a lack of systemized information related to the pathophysiology of the virus and its complications. Therefore, we selected publications on thromboembolic complications in patients with COVID19 , correlated them, and attempted to connect the data. Although

Address for Correspondence: Luigi Geo Marceanu, MD, Department of Medical and Surgical Specialties, Faculty of Medicine, Transilvania University of Brasov; 56, Nicolae Balcescu Str., 500019, Brasov-Romania Phone: +40744674478 E-mail: luigi-geo.marceanu@unitbv.ro

Accepted Date: 13.07.2021 Available Online Date: 09.08.2021 


\section{HIGHLIGHTS}

- In patients with coronavirus disease 2019 (COVID-19), endothelial inflammation is the trigger factor for thrombogenesis.

- Another mechanism of thrombus formation is the immune and nonimmune cellular response to the viral infection that creates an imbalance between pro and anticoagulant factors.

- The D-dimer level is correlated with prognosis and mortality.

- Heparin seems to be the best anticoagulant agent for patients with COVID-19 with a direct antiviral activity.

- A lot of advancements have occurred in telemedicine to cope with the COVID-19 pandemic.

a remarkable progress has been made since the onset of the pandemic, randomized studies in large groups of patients and development of therapeutic guidelines are still needed.

\section{Materials and methods}

We reviewed more than 190 abstracts, articles, and studies published on online platforms, such as MEDLINE/PubMed database, Google Scholar, ScienceDirect, Wiley Online Library, and Nature Public Health Emergency Collection. Of these, we selected only 53 articles that included articles that provided useful information on daily medical practice, studies that analyzed the pathophysiology of thrombus formation, and analyzed the risk factors for an unfavorable course of COVID-19 infection; and we discussed the stratification of the risk of pulmonary thromboembolism, the cardiovascular complications, the importance of D-dimers, and the effects of anticoagulant therapy in these patients. Remote monitoring strategies for patients with a chronic need for oral anticoagulant treatment were also noted. There was difficulty in maintaining the therapeutic value of international normalized ratio of prothrombin time (INR) in quarantined patients.

\section{Results and discussion}

A total of 2,784 related abstracts, articles, and studies were identified from the database. Of these, we excluded 721 repetitive publications. Of these, 531 records were excluded after the title or abstract review as they did not refer to the complications of the disease that we wanted to focus on. Furthermore, 142 articles were excluded because the main discussion was not related to our aims, they were not applicable in daily medical practice, they were clinical cases or a series of clinical cases, they were studies with fewer than 10 patients, or were articles with poor English translation. The remaining 53 studies and articles were closely evaluated and are cited in this review (Fig. 1) (3).

\section{Elements of pathophysiology in the COVID-19 infection associated thrombosis}

The Virchow triad is a fundamental concept of interaction between three components to create a favorable environment for thrombogenesis. All these components are also found in the COVID-19 infection and consist of blood flow abnormalities, vascular wall abnormalities, and the presence of circulating procoagulant compounds (4). Blood flow is altered by venous stasis caused by the prolonged bedrest (5). In COVID-19 associated coagulopathy, there is vascular inflammation and large endothelial dysfunction, followed by arterial, venous, or microcirculation thrombosis. Another feature of the COVID-19 coagulopathy is the significant increase in fibrin degradation products such as D-dimers, followed by platelet activation, aggregation, and thrombin generation which lead to the recruitment of the circulating platelets and the formation of thrombus (4). Thus, the high platelet reactivity has an important contribution in the occurrence of COVID-19 coagulopathy (6). In acute coronary syndromes, endothelial dysfunction, high platelet reactivity, and oxidative stress are significantly correlated $(7,8)$; although in patients with COVID-19 infection, endothelial inflammation is the trigger factor in the exacerbation of all these factors $(9,10)$.

In addition, the viral infection triggers an immune and nonimmune cellular response that creates an imbalance between pro and anticoagulant factors - another main mechanism of thrombus formation in COVID-19 infection (4).

The inflammation from the viral infection injures the vascular endothelium, increases the concentration of the von Willebrand factor, and activates toll-like receptors and the tissue factor leading to the onset of the coagulation cascade with formation of a fibrin clot (11). Inflammation can determine the expression of tissue factor at the level of the atrial endothelium too, thus stimulating the formation of intra-atrial thrombi $(12,13)$. The physiological response to the excessive activity of the coagulation cascade determines the disruption of the fibrin clot, leading to the release of D-dimers (10).

In patients with COVID-19, the D-dimer level has a good predictive value in identifying arterial or venous thrombosis $(14,15)$ and also correlates with the severity of disease, development of acute respiratory distress syndrome, and mortality (15). According to Al-Ani et al. (2), D-dimers have a dynamic evolution, their level increasing with the progression of the disease, and are significantly correlated with severe prognosis and mortality (16).

In COVID-19 coagulopathy, plasma levels of fibrinogen and platelet counts are, in the most patients, normal or elevated, differing from the disseminated intravascular coagulation characterized by low plasma fibrinogen levels and thrombocytopenia. This explains the lower incidence of bleeding in patients treated with anticoagulants. The occurrence of thrombocytopenia in patients with COVID-19 is a strong prognostic factor of the evolution toward multiple organ failure and disseminated intravascular coagulopathy (DIC). In patients with COVID-19, the severe evolution with DIC seems to be the result of cumulative factors that induce sepsis and prothrombotic status $(4,17)$. 

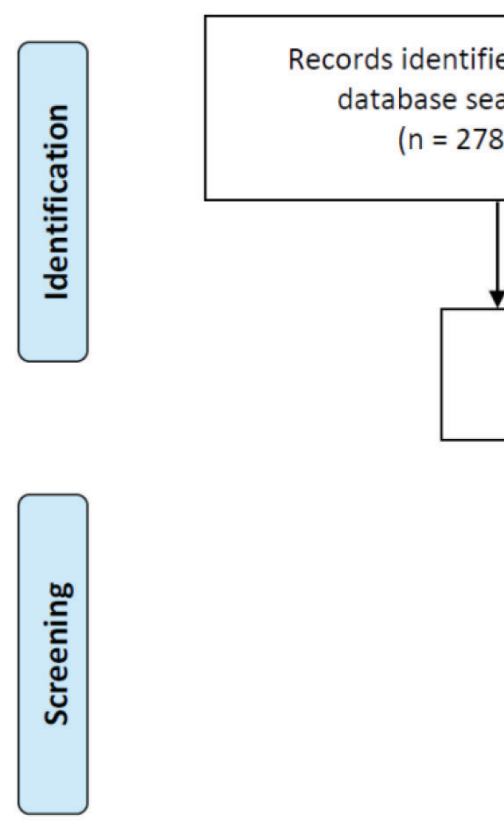

Records after duplicates removed

$(n=721)$

Additional records identified through other sources

$(n=0)$
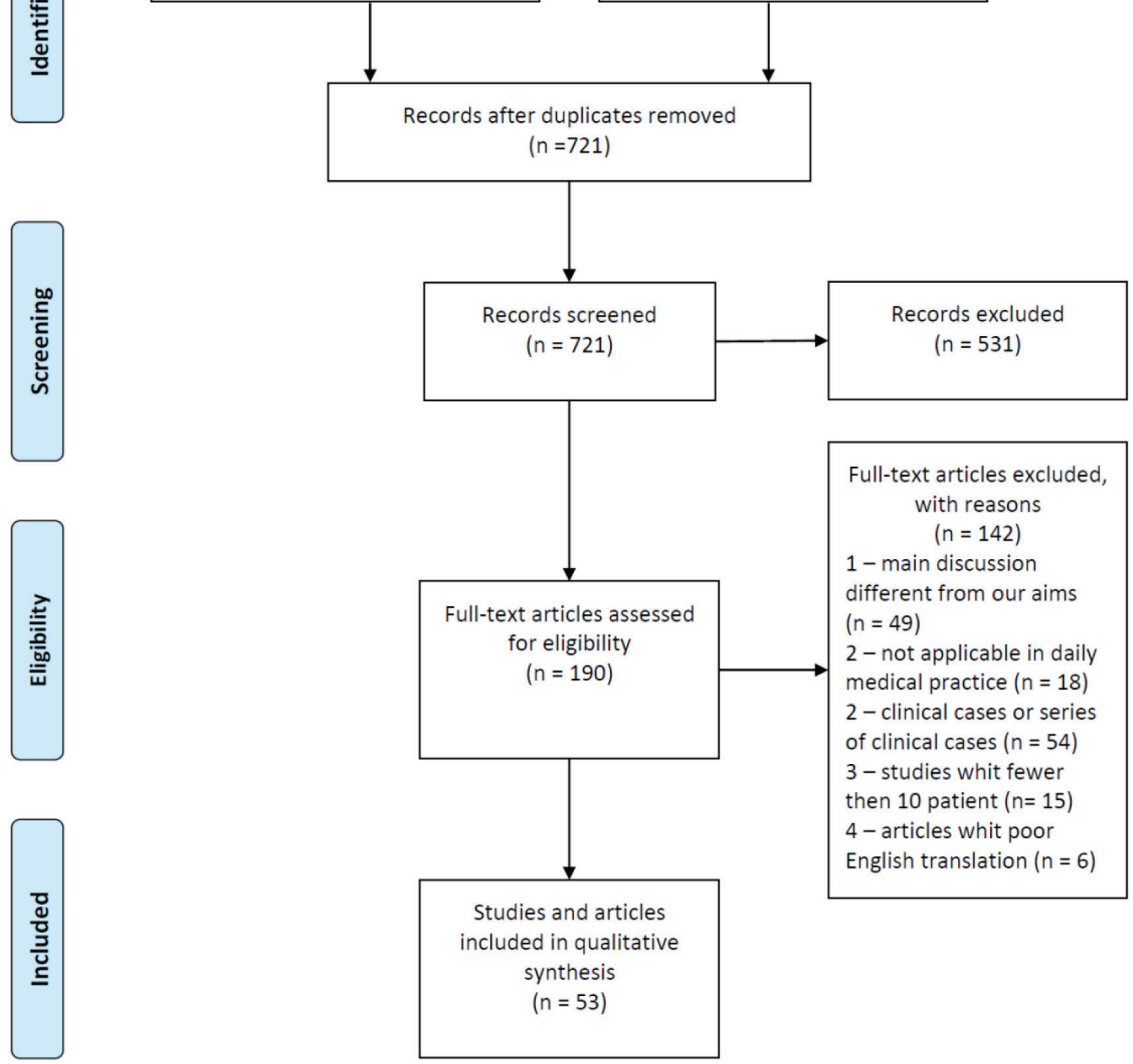

Full-text articles excluded, with reasons

( $n=142$ )

1 - main discussion different from our aims ( $n=49$ ) 2 - not applicable in daily medical practice $(n=18$ ) 2 - clinical cases or series of clinical cases $(n=54)$ 3 -studies whit fewer then 10 patient $(n=15)$ 4-articles whit poor

English translation $(n=6)$

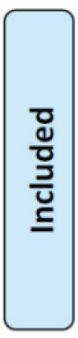

Figure 1. The flow diagram showing the selection process according to the preferred reporting items for systematic reviews and meta-analysis statement (3)

Finally, in COVID-19 infection, the platelets, in addition to their prothrombotic action mediated by classical platelet receptors, also have a platelet receptor-mediated hemostatic effect with an important role in the endothelial barrier protection and micro-vascular integrity (18).

\section{Risk factors and complications associated with the negative evolution of patients with COVID-19 infection}

Patients with cardiac pathology or cardiovascular risk factors (such as old age, diabetes, or neoplastic disease) are sus- ceptible to an unfavorable evolution toward COVID-19 infection. At the same time, the COVID-19 infection itself can lead to many cardiovascular diseases (19-21). Inciardi et al. (22) conducted the first clinical study that described the characteristics and evolution of patients with a history of cardiac pathology and COVID-19 pneumonia. The study was conducted on the population of northern Italy and it concluded that patients with heart disease hospitalized for COVID-19 had a poorer prognosis compared with patients without a history of cardiac pathology. They had a higher rate of mortality, thromboembolic events, and septic shock ( $36 \%$ vs. $15 \%$ mortality and $57 \%$ vs. $21 \%$ major compli- 
cations overall). It is believed that the cardiovascular and respiratory systems have an equal role to play in the pathogenesis of COVID-19 infection (23). Although most suffer respiratory symptoms, a considerable number of patients develop various cardiovascular complications. In a study conducted by Gavioli et al. (19) it was observed that approximately $20 \%$ of hospitalized infected patients suffered cardiac injury defined by an increase in cardiac biomarkers above the 99th percentile upper reference limit) with the appearance of acute coronary syndromes as a complication of COVID-19 infection (4). The most common complications were arrhythmia, arterial and venous thromboembolism (VTE), cerebrovascular injury, fulminant myocarditis, and heart failure that could evolve to cardiogenic shock $(20,24,25)$. Neurological signs, including headaches, anosmia, nausea, dysgeusia, damage to respiratory centers, and cerebral infarction were also reported in patients with severe acute respiratory syndrome coronavirus 2 (SARS-Cov-2) infection (26). One report of the Italian National Institute of Health showed that $25 \%$ of the patients who died of COVID-19 had atrial fibrillation, ranking it as the fourth most common pathology associated with these patients. The New York State Department of Health reported that atrial fibrillation ranked as the seventh most frequent comorbidity among patients with COVID-19 (27). Holt et al. (28) conducted an analysis of medical records in Denmark by comparing the number of newly diagnosed patients with atrial fibrillation during the first three months of 2019 and 2020. There was a $47 \%$ decrease of newly diagnosed patients with atrial fibrillation during the quarantine period, suggesting a concomitant increase in undiagnosed patients. In these patients, a lack of treatment could lead to complications of atrial fibrillation, the most feared being stroke, favored by the prothrombotic status in patients with COVID 19.

One of the mechanisms involved in the occurrence of arrhythmias in patients with COVID-19 is hypoxia, which causes anaerobic glycolysis, resulting in reduced intracellular $\mathrm{pH}$ and increased cytosolic calcium levels. This favors an early or delayed depolarization of the myocyte and can also cause a transient alteration of the duration of the action potential. In addition, hypoxia also increases the level of extracellular potassium, which lowers the depolarization threshold and thus accelerates electrical conduction (29).

Another trigger for arrhythmias is the systemic inflammatory process. This favors the formation of myocardial tissue fibrosis and consequently alters the electrical properties of the atrial myocardium $(12,30)$.

\section{Screening and diagnosis of thromboembolism in patients with COVID-19 infection}

One of the main challenges faced by physicians in patients with COVID-19 is the prevention and early diagnosis of VTE given the fact that there is still no standardized protocol to administer anticoagulant treatment to these patients (21). Llitjos et al. (31) have suggested performing systematic screening for VTE and early initiation of anticoagulation at therapeutic doses in patients with severe COVID-19 infection because of its increased thrombogenicity. In this study, a systematic screening strategy using complete venous Doppler echography of patients with COVID-19, treated in intensive care units between the first and third day after admission, was implemented. The patients who were not diagnosed with VTE during the first screening had venous Doppler echography repeated on the seventh day. All the patients received anticoagulant treatment with unfractionated heparin (UFH) or low molecular weight heparin (LMWH) in prophylactic or therapeutic doses, depending on the risk of thrombosis and bleeding associated with each patient. Venous Doppler echography was performed according to current guidelines, assessing the venous circulation from the thigh to the ankles. Pulmonary thromboembolism was systematically sought in patients with persistent respiratory failure who were evaluated using pulmonary arteriography, computed tomography, or trans-esophageal echocardiography if they were immobile. The study reported $69 \%$ incidence of peripheral VTE and $23 \%$ pulmonary VTE. The proportion of patients with VTE was significantly higher in the group treated with prophylactic doses of anticoagulant than in the group treated with therapeutic doses $(100 \%$ vs. $56 \%$ ) (31).

In a study conducted in 24 hospitals in France, including 2,878 patients with COVID-19 infection who were hospitalized consecutively, 1,240 patients were admitted into the study after excluding those who did not undergo pulmonary angiography or computed tomography to prove pulmonary thromboembolism and those who were admitted directly to the intensive care unit. Of the 1,240 patients, $8.3 \%$ were diagnosed with pulmonary thromboembolism, and the diagnosis was confirmed within the first 48 hours of hospitalization in $77.7 \%$ (1).

Owing to the fact that the incidence of VTE is significantly higher in COVID-19 infection, venous embolism screening should be considered, both in patients with a very severe clinical condition with a need for admission to intensive care units and for those with a less severe clinical condition. However, such procedures are difficult to implement because these patients are isolated (16).

\section{Effects of anticoagulants in patients with COVID-19 infection}

UFH and LMWH have both been shown to be the most effective anticoagulant agents for patients with COVID-19. Along with its anticoagulant role, heparin has the following two advantages; the ability to bind to viral proteins and participate in the downregulation of proinflammatory cytokines $(32,33)$, whose levels are high in patients with COVID-19 infection (22).

Heparin appears to have a direct antiviral activity by binding to the viral protein S (spike) preventing the virus from fusing with the angiotensin-converting enzyme 2 (ACE2) receptor needed for intracellular penetration. Thus, heparin behaves as a competitive inhibitor $(15,34,35)$. The ACE2 receptor is expressed both within the lungs and at the level of the cardiovascular system and has a critical role in the cardioprotective function of the renin-angiotensin-aldosterone system (36). The genome of 
the COVID-19 virus has been identified in postmortem autopsy of cardiac anatomical samples, suggesting a prompt viral infiltration of the myocardial tissue during infection (37). A marked decrease in the expression of ACE2 receptors simultaneously with an increase in the number of inflammatory cells and the level of fibrosis was also observed in these samples $(10,38,39)$.

Given the fact that ACE2 inhibitors represent an important therapeutic line for heart disease with proven beneficial effects and given the limitations of knowing the interactions of the virus with these drugs, continuing the treatment with ACE2 inhibitors in patients with clinical indications is recommended (20). Data about the use of ACE inhibitors (ACEls) or angiotensin-receptor blockers (ARBs) in COVID-19 infection for prevention and treatment are contradictory. Some studies have suggest that ACEls/ ARBs may exacerbate the effects of the infection, whereas others with results from animal studies and clinical trials have highlight their efficacy during COVID-19 infection in patients with other comorbidities, such as heart failure, hypertension, diabetes, and renal disease. Most of these studies have demonstrated the effectiveness of ACEls or ARBs in preventing COVID19 viral entry by stabilizing ACE2-AT1R interaction and preventing the viral protein-ACE2 interaction and internalization. However, some studies have also demonstrated that SARSCoV-2 down-regulates ACE2 expression and thus decreases the protective effects of ACE2 on different organs $(40,41)$.

Reduction of the inflammatory response by heparin in patients with COVID-19 is achieved by inhibiting neutrophil activation, preventing both the expression of inflammatory mediators in the vascular endothelium and the proliferation of vascular smooth muscle cells (42). Adam Torbicki's (43) editorial has discussed how the inflammatory response is a major determinant of pulmonary thromboembolism in COVID-19 infection.

According to the algorithm established by the European Society of Cardiology in the management of COVID-19 coagulopathy, the criteria for increased risk of thromboembolism include dyspnea; oxygen saturation less than $90 \%$; respiratory rate greater than 24 breaths/min; high level of C-reactive protein; and increased values of D-dimers, fibrinogen, and platelets $(5$, 44). The International Society of Thrombosis and Hemostasis and the American Society of Hematology recommend that all the patients hospitalized with COVID-19 infection should receive LMWH for thromboprophylaxis $(18,45)$.

Tang et al. (46) have shown through a retrospective analysis of 449 patients infected with COVID-19, that in 99 of these patients, the administration of LMWH was correlated with a reduction in mortality. The patients whose levels of D-dimers were more than six times the upper limit of normal had the same benefit. This report highlighted the benefit of starting anticoagulant treatment in patients with COVID-19 with a score of sepsisinduced coagulopathy $\geq 4$ or with a level of D-dimers $>3 \mu \mathrm{g} / \mathrm{ml}$. These results are reinforced by another study that was conducted in 17 hospitals in Spain led by Ayerbe et al. (47), which also found that heparin administration was associated with a lower mortality in patients with COVID-19 infection.

\section{Impact of chronic anticoagulant treatment in patients with COVID-19 infection}

For patients on chronic oral anticoagulant treatment for other pathologies, switching to LMWH or UFH during COVID-19 infection is recommended because of the anti-inflammatory and antiviral properties of heparin. Moreover, as p-glycoprotein and cytochrome P450 pathways metabolize direct oral anticoagulants (DOACs) and vitamin K antagonists (VKA), they can cause drug interactions with the antiviral agents (19). Testa et al. (48) have shown that the plasma levels of DOACs during the treatment of patients with COVID-19 are six times higher during hospitalization than in the period before hospitalization, probably owing to drug-drug interactions. Unlike the oral anticoagulants, the parenteral anticoagulants do not show major drug interactions with antiviral drugs.

The thrombotic vascular processes complicate severe SARS-COV-2 infection. The role of chronic anticoagulant therapy before COVID-19 infection and its impact in decreasing the thrombotic risk has not yet been systematically studied. Therefore, Lachant et al. (49) have suggested in a retrospective study that chronic anticoagulant treatment received for at least 1 month before COVID-19 infection may protect against new thrombotic events and may decrease the severity of the disease. In this study, $61 \%$ of the patients did not require hospitalization. Although these patients were at increased risk of developing new thrombosis, they did not experience any new thrombotic events. Furthermore, the anticoagulant treatment did not cause any unexpected bleeding, nor was there an increased rate of bleeding. Another finding was that, for hospitalized patients, the median level of D-dimers was lower compared with that of other cohorts of hospitalized patients reported in the literature. Middeldorp et al. (50) have followed 198 patients hospitalized for COVID-19, 20\% of whom were diagnosed with VTE in the first 7 days of hospitalization, although they were given anticoagulant therapy at prophylactic doses. For them, the cumulative incidence of VTE at 7, 14, and 21 days was of $16 \%, 33 \%$, and $42 \%$, respectively. They mentioned that no thrombotic events were found in hospitalized patients who were already using chronic anticoagulant therapy. Consistent with the above-mentioned results, Poissy et al. (51) have shown that of the 22 patients with SARS-COV-2 whose evolution was complicated by pulmonary thromboembolism, only two were on chronic anticoagulant therapy. In addition to this data, in a report by Klok et al. (52) on 184 patients, it was observed that the incidence of pulmonary thromboembolism was lower in patients on chronic anticoagulation treatment. Similarly, Fauvel et al. (1), in a multicenter study including 1,240 patients hospitalized consecutively for COVID-19 infection, have observed that inpatients treated with anticoagulant agents before the infection had a lower rate of pulmonary thromboembolism. Of the patients included in the study, 103 (8.3\%) developed pulmonary thromboembolism; and $136(11 \%)$ patients were on chronic anticoagulation treatment with heparin, VKA, or DOACs, and only $5(4.9 \%)$ of them developed pulmonary thromboembolism. 
The American College of Cardiology considers it reasonable to extend the period of thromboembolic prophylaxis after discharge for high-risk patients (reduced mobility, increased level of D-dimers at discharge, and associated comorbidities) (4). For outpatients, using bleeding scores along with risk scores for VTE followed by treatment with apixaban $2.5 \mathrm{mg}$ twice daily or rivaroxaban $10 \mathrm{mg}$ daily for 2 weeks is recommended (19). For those with a chronic need for anticoagulants, the current crisis brings multiple arguments in favor of DOACs for patients without contraindications. For patients on longterm VKA drugs, this represents an opportunity to change to DOACs. Hermans and Lambert (53) have recommended that point-of-care devices should be implemented for measuring the INR value for patients who must remain on VKA drugs (such as those with advanced chronic kidney disease, mechanical valve prostheses, and antiphospholipid syndrome). The importance of this fact is underlined by Speed et al. (54) who observed that coumarin overdose is more common during quarantine than in the period when people could easily go to the medical analysis laboratory. Owing to this current situation, a communication system with three important components has been developed: (a) a structured teleconsultation ('Tele'); (b) an app-based on-demand heart rate and rhythm monitoring infrastructure ('Check'); and (c) comprehensive AF management ('AF') (TeleCheck-AF) to speak easily with patients who are known to have atrial fibrillation to transmit the INR value to the medical staff. It is a recently implemented program and therefore it has not been possible to assess its effectiveness in controlling INR values thus far (55).

\section{Conclusion}

D-dimers can be used as an important tool in the clinical trial of each case, having the following advantages; predictive value for identifying thrombosis, and at high levels, significant correlation with infection severity, progression to SARS-CoV-2, and, mortality.

All the studies have shown the benefit of LMWH in patients with thromboembolic risk factors and hospitalized for COVID-19 infection. Heparin has other favorable effects along with anticoagulation, including direct antiviral activity and anti-inflammatory effect. The risk of bleeding should be assessed for each patient.

Patients already receiving chronic anticoagulant therapy for other pathologies have a better outcome for COVID-19 infection and have a lower rate of adverse events. During the treatment of the infection, oral anticoagulant medication must be changed to parenteral treatment.

This crisis has mobilized the medical system to develop a telemedicine system for effective access to medical services and to monitor patient evolution.

Conflict of interest: None declared.

Peer-review: Externally peer-reviewed.
Author contributions: Concept - E.B., L.G.M., A.C., L.A.V.; Design E.B., L.G.M., A.C., L.A.V.; Supervision - E.B., L.G.M., A.C., L.A.V.; Fundings - None; Materials - E.B., L.G.M., A.C., L.A.V.; Data collection \&/or processing - E.B., L.G.M., A.C., L.A.V.; Analysis \&/or interpretation - E.B., L.G.M., A.C., L.A.V.; Literature search - E.B., L.G.M., A.C., L.A.V.; Writing - E.B., L.G.M., A.C., L.A.V.; Critical review - E.B., L.G.M., A.C., L.A.V.

\section{References}

1. Fauvel C, Weizman O, Trimaille A, Mika D, Pommier T, Pace N, et al. Pulmonary embolism in COVID-19 patients: a French multicentre cohort study. Eur Heart J 2020; 41: 3058-68. [Crossref]

2. Al-Ani F, Chehade S, Lazo-Langner A. Thrombosis risk associated with COVID-19 infection. A scoping review. Thromb Res 2020; 192: 152-60. [Crossref]

3. Moher D, Liberati A, Tetzlaff J, Altman DG; PRISMA Group. Preferred reporting items for systematic reviews and meta-analyses: the PRISMA statement. PLoS Med 2009; 6: e1000097. [Crossref]

4. Becker RC. COVID-19 update: Covid-19-associated coagulopathy. J Thromb Thrombolysis 2020; 50: 54-67. [Crossref]

5. Atallah B, Mallah SI, AIMahmeed W. Anticoagulation in COVID-19. Eur Heart J Cardiovasc Pharmacother 2020; 6: 260-1. [Crossref]

6. Manne BK, Denorme F, Middleton EA, Portier I, Rowley JW, Stubben $\mathrm{C}$, et al. Platelet gene expression and function in patients with COVID-19. Blood 2020; 136: 1317-29. [Crossref]

7. Bobescu E, Covaciu A, Rus H, Radoi M, Badea M, Moga SN, et al. Correlation of Cardiovascular Risk Factors and Biomarkers With Platelet Reactivity in Coronary Artery Disease. Am J Ther 2019; 26 : 563-9. [Crossref]

8. Bobescu E, Covaciu A, Rus H, Rogozea LM, Badea M, Marceanu LG. Low Response to Clopidogrel in Coronary Artery Disease. Am J Ther 2020; 27: e133-41. [Crossref]

9. Hottz ED, Azevedo-Quintanilha IG, Palhinha L, Teixeira L, Barreto EA, Pão CRR, et al. Platelet activation and platelet-monocyte aggregate formation trigger tissue factor expression in patients with severe COVID-19. Blood 2020; 136: 1330-41. [Crossref]

10. Nuche J, Segura de la Cal T, Jiménez López Guarch C, LópezMedrano F, Delgado CP, Ynsaurriaga FA, et al. Effect of Coronavirus Disease 2019 in Pulmonary Circulation. The Particular Scenario of Precapillary Pulmonary Hypertension. Diagnostics (Basel) 2020; 10: 548. [Crossref]

11. Giannis D, Ziogas IA, Gianni P. Coagulation disorders in coronavirus infected patients: COVID-19, SARS-CoV-1, MERS-CoV and lessons from the past. J Clin Virol 2020; 127: 104362. [Crossref]

12. Lüscher TF. Understanding COVID-19: in the end it is the endothelium-what else? Eur Heart J 2020; 41: 3023-7. [Crossref]

13. Steffel J, Lüscher TF, Tanner FC. Tissue factor in cardiovascular diseases: molecular mechanisms and clinical implications. Circulation 2006; 113: 722-31. [Crossref]

14. Betoule A, Martinet C, Gasperini G, Muller P, Foucher S, Benner P, et al. Diagnosis of venous and arterial thromboembolic events in COVID-19 virus-infected patients. J Thromb Thrombolysis 2020; 50 : 302-4. [Crossref]

15. Nauka PC, Oran E, Chekuri S. Deep venous thrombosis in a noncritically ill patient with novel COVID-19 infection. Thromb Res 2020; 192: 27-8. [Crossref]

16. Zamboni P. COVID-19 as a Vascular Disease: Lesson Learned from Imaging and Blood Biomarkers. Diagnostics (Basel) 2020; 10: 440. [Crossref] 
17. Marchandot B, Sattler L, Jesel L, Matsushita K, Schini-Kerth V, Grunebaum L, et al. COVID-19 Related Coagulopathy: A Distinct Entity? J Clin Med 2020; 9: 1651. [Crossref]

18. Smeda M, Chlopicki S. Endothelial barrier integrity in COVID-19dependent hyperinflammation: does the protective facet of platelet function matter? Cardiovasc Res 2020; 116: e118-21. [Crossref]

19. Gavioli EM, Sikorska G, Man A, Rana J, Vider E. Current Perspectives of Anticoagulation in Patients With COVID-19. J Cardiovasc Pharmacol 2020; 76: 146-50. [Crossref]

20. Ky B, Mann DL. COVID-19 Clinical Trials: A Primer for the Cardiovascular and Cardio-Oncology Communities. JACC Basic Transl Sci 2020; 5: 501-17. [Crossref]

21. Porfidia A, Pola R. Venous Thromboembolism and Heparin Use in COVID-19 Patients: Juggling between Pragmatic Choices, Suggestions of Medical Societies and the Lack of Guidelines. J Thromb Thrombolysis 2020; 50: 68-71. [Crossref]

22. Inciardi RM, Adamo M, Lupi L, Cani DS, Di Pasquale M, Tomasoni $D$, et al. Characteristics and outcomes of patients hospitalized for COVID-19 and cardiac disease in Northern Italy. Eur Heart J 2020; 41: 1821-9. [Crossref]

23. Zhou F, Yu T, Du R, Fan G, Liu Y, Liu Z, et al. Clinical course and risk factors for mortality of adult inpatients with COVID-19 in Wuhan, China: a retrospective cohort study. Lancet 2020; 395: 1054-62. [Crossref]

24. Kang Y, Chen T, Mui D, Ferrari V, Jagasia D, Scherrer-Crosbie M, et al. Cardiovascular manifestations and treatment considerations in COVID-19. Heart 2020; 106: 1132-41. [Crossref]

25. Mao L, Jin H, Wang M, Hu Y, Chen S, He O, et al. Neurologic Manifestations of Hospitalized Patients With Coronavirus Disease 2019 in Wuhan, China. JAMA Neurol 2020; 77: 683-90. [Crossref]

26. Jarrahi A, Ahluwalia M, Khodadadi H, da Silva Lopes Salles E, Kolhe R, Hess DC, et al. Neurological consequences of COVID-19: what have we learned and where do we go from here? J Neuroinflammation 2020; 17: 286. [Crossref]

27. Sanchis-Gomar F, Perez-Quilis C, Lavie CJ. Should atrial fibrillation be considered a cardiovascular risk factor for a worse prognosis in COVID-19 patients? Eur Heart J 2020; 41: 3092-3. [Crossref]

28. Holt A, Gislason GH, Schou M, Zareini B, Biering-Sørensen $T$, Phelps $M$, et al. New-onset atrial fibrillation: incidence, characteristics, and related events following a national COVID-19 lockdown of 5.6 million people. Eur Heart J 2020; 41: 3072-9. [Crossref]

29. Dherange $P$, Lang J, Qian P, Oberfeld B, Sauer WH, Koplan B, et al. Arrhythmias and COVID-19: A Review. JACC Clin Electrophysiol 2020; 6: 1193-204. [Crossref]

30. Lazzerini PE, Laghi-Pasini F, Acampa M, Srivastava U, Bertolozzi I, Giabbani B, et al. Systemic Inflammation Rapidly Induces Reversible Atrial Electrical Remodeling: The Role of Interleukin-6-Mediated Changes in Connexin Expression. J Am Heart Assoc 2019; 8: e011006. [Crossref]

31. Llitjos JF, Leclerc M, Chochois C, Monsallier JM, Ramakers M, Auvray $\mathrm{M}$, et al. High incidence of venous thromboembolic events in anticoagulated severe COVID-19 patients. J Thromb Haemost 2020; 18: 1743-6. [Crossref]

32. Ranucci M, Ballotta A, Di Dedda U, Bayshnikova E, Dei Poli M, Resta $\mathrm{M}$, et al. The procoagulant pattern of patients with COVID-19 acute respiratory distress syndrome. J Thromb Haemost 2020; 18 : 1747-51. [Crossref]

33. Mummery RS, Rider CC. Characterization of the heparin-binding properties of IL-6. J Immunol 2000; 165: 5671-9. [Crossref]
34. Hippensteel JA, LaRiviere WB, Colbert JF, Langouët-Astrié CJ, Schmidt EP. Heparin as a therapy for COVID-19: current evidence and future possibilities. Am J Physiol Lung Cell Mol Physiol 2020; 319: L211-7. [Crossref]

35. Shah SMA, Rasheed T, Rizwan K, Bilal M, Iqbal HMN, Rasool N, et al. Risk management strategies and therapeutic modalities to tackle COVID-19/SARS-CoV-2. J Infect Public Health 2021; 14: 33146. [Crossref]

36. Ganatra S, Hammond SP, Nohria A. The Novel Coronavirus Disease (COVID-19) Threat for Patients With Cardiovascular Disease and Cancer. JACC CardioOncol 2020; 2: 350-5. [Crossref]

37. Oudit GY, Kassiri Z, Jiang C, Liu PP, Poutanen SM, Penninger JM, et al. SARS-coronavirus modulation of myocardial ACE2 expression and inflammation in patients with SARS. Eur J Clin Invest 2009; 39: 618-25. [Crossref]

38. Oudit GY, Pfeffer MA. Plasma angiotensin-converting enzyme 2: novel biomarker in heart failure with implications for COVID-19. Eur Heart J 2020; 41: 1818-20. [Crossref]

39. Schreiber B, Patel A, Verma A. Shedding Light on COVID-19: ADAM17 the Missing Link? Am J Ther 2020 Aug 3. doi: 10.1097/ MJT.00000000000001226. [Epub ahead of print] [Crossref]

40. Yehualashet AS, Belachew TF. ACEls and ARBs and Their Correlation with COVID-19: A Review. Infect Drug Resist 2020; 13: 3217-24. [Crossref]

41. Chowdhury MA, Hossain N, Kashem MA, Shahid MA, Alam A. Immune response in COVID-19: A review. J Infect Public Health 2020; 13: 1619-29. [Crossref]

42. Poterucha TJ, Libby P, Goldhaber SZ. More than an anticoagulant: Do heparins have direct anti-inflammatory effects? Thromb Haemost 2017; 117: 437-44. [Crossref]

43. Torbicki A. COVID-19 and pulmonary embolism: an unwanted alliance. Eur Heart J 2020; 41: 3069-71. [Crossref]

44. Mazzaccaro D, Giacomazzi F, Giannetta M, Varriale A, Scaramuzzo $R$, Modafferi A, et al. Non-Overt Coagulopathy in Non-ICU Patients with Mild to Moderate COVID-19 Pneumonia. J Clin Med 2020; 9: 1781. [Crossref]

45. Ambrosino P, Di Minno A, Maniscalco M, Di Minno MND. COVID-19 and venous thromboembolism: current insights and prophylactic strategies. Ann Med 2020; 52: 239-42. [Crossref]

46. Tang N, Bai H, Chen X, Gong J, Li D, Sun Z. Anticoagulant treatment is associated with decreased mortality in severe coronavirus disease 2019 patients with coagulopathy. J Thromb Haemost 2020; 18: 1094-9. [Crossref]

47. Ayerbe L, Risco C, Ayis S. The association between treatment with heparin and survival in patients with Covid-19. J Thromb Thrombolysis 2020; 50: 298-301. [Crossref]

48. Testa S, Prandoni P, Paoletti O, Morandini R, Tala M, Dellanoce C, et al. Direct oral anticoagulant plasma levels' striking increase in severe COVID-19 respiratory syndrome patients treated with antiviral agents: The Cremona experience. J Thromb Haemost 2020; 18: 1320-3. [Crossref]

49. Lachant DJ, Lachant NA, Kouides P, Rappaport S, Prasad P, White RJ. Chronic therapeutic anticoagulation is associated with decreased thrombotic complications in SARS-CoV-2 infection. J Thromb Haemost 2020; 18: 2640-5. [Crossref]

50. Middeldorp $S$, Coppens $M$, van Haaps TF, Foppen M, Vlaar AP Müller MCA, et al. Incidence of venous thromboembolism in hospitalized patients with COVID-19. J Thromb Haemost 2020; 18: 19952002. [Crossref] 
51. Poissy J, Goutay J, Caplan M, Parmentier E, Duburcq T, Lassalle F, et al.; Lille ICU Haemostasis COVID-19 Group. Pulmonary Embolism in Patients With COVID-19: Awareness of an Increased Prevalence. Circulation 2020; 142: 184-6. [Crossref]

52. Klok FA, Kruip MJHA, van der Meer NJM, Arbous MS, Gommers $D$, Kant KM, et al. Confirmation of the high cumulative incidence of thrombotic complications in critically ill ICU patients with COVID-19: An updated analysis. Thromb Res 2020; 191: 148-50. [Crossref]
53. Hermans C, Lambert C. Impact of the COVID-19 pandemic on therapeutic choices in thrombosis-hemostasis. J Thromb Haemost 2020; 18: 1794-5. [Crossref]

54. Speed V, Patel RK, Byrne, Roberts LN, Arya R. A perfect storm: Root cause analysis of supra-therapeutic anticoagulation with vitamin $\mathrm{K}$ antagonists during the COVID-19 pandemic. Thromb Res 2020; 192 : 73-4. [Crossref]

55. Linz D, Pluymaekers NAHA, Hendriks JM. TeleCheck-AF for COVID19. Eur Heart J 2020; 41: 1954-5. [Crossref] 